\title{
How Does Motivation Develop and Why Does It Change? Reframing Motivation Research
}

\author{
Julianne C. Turner \\ Psychology Department \\ University of Notre Dame \\ Helen Patrick \\ Department of Educational Studies \\ Purdue University
}

\begin{abstract}
In this article, we argue for a change in how researchers study motivation to learn. We believe that research can provide better explanations of the origins and outcomes of behavior, and thus be more useful, if we focus on how motivation develops and why it changes. We suggest reframing motivation research in education by extending the current focus on beliefs to studying the transactions among persons engaged in specific classroom activities over time. We present one approach from developmental psychology-Rogoff's three planes - that attempts to account for this transaction. We then present examples of current motivation research to illustrate how this approach has been applied. We believe that using this framework can produce new results that are meaningful for both researchers and practitioners who want to understand and foster motivation in education.
\end{abstract}

Consider the motivation of two students in the same sixthgrade mathematics classroom. One is a low-achieving girl and the other a high-achieving boy. When asked to report on their achievement goals on a survey, the girl reported high personal mastery ${ }^{1}$ and low performance-approach goals. In contrast, the boy reported high personal performanceapproach goals and moderate mastery goals. They construed the goals emphasized in their classroom differently: The girl perceived a relatively high emphasis on learning and improvement, whereas the boy did not see those goals as particularly valued in the classroom. Both agreed that the emphasis on demonstrating one's ability was salient in their classroom (Turner \& Patrick, 2004). What predictions might we make about these students' effort, persistence, and affect? In particular, how might they view themselves as mathematics learners, how might they participate in classroom activities, and what kind of affective reactions would classroom membership invoke?

Correspondence should be addressed to Julianne C. Turner, Psychology Department, University of Notre Dame, 103 Haggar Hall, Notre Dame, IN 46556. E-mail: jturner3@nd.edu

${ }^{1}$ Personal mastery goals refer to a goal to learn and improve. Personal performance approach goals refer to a goal to demonstrate competence by outperforming others.
Based on research in achievement goal theory, we venture the following hypotheses. The girl, although low achieving, would seek to participate often and to improve. Because she construed a high emphasis on learning in her classroom, she would feel supported in her motivation to learn, and she would employ effective learning strategies, such as asking questions when confused, demonstrating positive affect based on her effort, and valuing mathematics learning. Conversely, because he viewed the emphasis on outperforming others as high and because he wanted to demonstrate his ability and protect his self-worth, the boy would participate strategically, opting for questions he could answer easily. $\mathrm{He}$ might avoid asking for help and might be reluctant to put forth a great deal of effort, even when he was confused. He would show positive affect when he experienced success but negative affect when his competence was threatened, and he would value mathematics more for its potential to showcase his "success" than for what he could learn or use.

How accurate are these hypotheses and what kinds of generalizations might we make about these students? We found that these hypotheses, although based on a fruitful theory of motivation and reliable survey measures, were not adequate to explain the students' behaviors and emotions in their sixth-grade classroom, nor were similar measures able to predict the change in their participation in their seventh-grade 
classrooms. How can we explain this? Follow us into the classroom.

In sixth grade, the girl, Shanida, volunteered in class somewhat frequently, but she was often incorrect. It was not uncommon for the teacher to move on quickly to another student for the correct answer. Once, when Shanida confused a $30^{\circ}$ and a $45^{\circ}$ angle, the teacher publicly ridiculed her lack of understanding. When Shanida asked for clarification, the teacher became exasperated, and declared "They're not the same!" providing no explanation. Justin, the boy, appeared to have a quite different experience. He rarely volunteered, but the teacher called on him frequently (as many as 10 times during one class) and required him to participate. When he wanted to shirk responsibility for thinking, calling a problem "impossible," the teacher insisted that he persevere and scaffolded his (reluctant) attempts. Justin protested that the teacher expected him to do "eighth-grade work." She reminded him that he was able by publicly disclosing his upcoming placement in the advanced seventh-grade math class and by noting that he was selected to participate in Mathematics Quiz Bowl.

In seventh grade, the students' worlds changed. Shanida found herself in an "average-level" mathematics class where the teacher emphasized understanding and supported the students' thinking, even when it was uncertain and halting. Shanida's participation increased and was acknowledged. Given opportunities to work with others and to attempt problem solving, she earned this delighted accolade from her teacher: "Ohhhhhh, this is a clever girl. That is a good strategy." By the end of the year Shanida had assumed a leadership role. For example, she suggested changing a class project to make it more meaningful for students, and the teacher readily agreed. In contrast to the previous year, Justin was almost invisible in his seventh-grade advanced math class. He volunteered to answer a question only once in the six lessons he was observed. Furthermore, on occasions when the teacher did call on him, it was more often to encourage him to put forth more effort or to scold him for his behavior. Justin was mostly an observer in his classroom.

How well do the students' motivational self-reports explain and predict their very different behaviors in both sixth and seventh grades? Although Shanida reported strong personal mastery goals in both years, her learning-oriented behaviors were much more evident in seventh grade. At the same time, she perceived her seventh-grade classroom, which was more supportive of her engagement, as less mastery focused than her sixth-grade classroom. Justin's participation also did not seem consistent with the high performanceapproach goal orientations he reported. His sixth-grade teacher valued correct answers, and he was one of the highest achievers in his class, suggesting that he might take the many opportunities offered to outperform his peers. But his teacher mostly "forced" him to participate. In seventh grade, Justin reported lower performance-approach goals, perhaps consistent with his perception of the lower focus on relative ability in the classroom. His goals suggest that he would answer questions to appear smart but not be especially concerned about learning and not intend to avoid engagement. Yet he did not take advantage of the opportunities to demonstrate competence, even though mistakes were viewed benignly and participation was high in this classroom. It is difficult to explain the change in the students' behaviors using measures of their beliefs alone. Although they reported mostly minor changes in personal goals, the students' participation changed dramatically from one year to the next.

Our analyses of these students' participation suggest that to understand what the students did, why they did it, and how their behaviors changed throughout the 2 years, we need also to understand the classroom norms and the interpersonal events, including their affordances and constraints. This study indicated that students' classroom participation is not a manifestation of their (existing) beliefs; rather, students' participation changes as beliefs develop and change in concert with opportunities that are made available to, or required of, students by other classroom participants. In the case of Justin and Shanida, some influential factors in both years appeared to be teachers' expectations for their students, whether they called on all or only some students, and whether teachers actively supported student thinking and participation. The ongoing interplay between students' socially situated construals and their circumstances provide better explanations of their participation.

In sixth grade, Justin was accorded high ability by the teacher, and she directed special instructional and motivational support to him - support not offered to others - that may have enabled him to participate successfully and achieve. In fact, Justin was required to participate. In seventh grade Justin rarely volunteered and was mostly ignored. Perhaps he annoyed the teacher, but she also called mostly on volunteers. "Lying low" may have supported Justin's goal of looking able, as he rarely subjected himself to public evaluation, but it was the teacher's particular practices that "allowed" Justin to opt out. In Shanida's case, low achievement and frequent mistakes appeared to evoke low expectations from the sixth-grade teacher, who called on her infrequently and bypassed opportunities to help her learn. Although Shanida appeared to try hard and cooperate, her efforts were ridiculed at least once and probably frustrated overall. In seventh grade, the teacher supported her instructionally and motivationally by inviting her to participate, by encouraging her, and by recognizing her growth. This affordance was consistent with Shanida's expressed goal to improve. Having observed Justin or Shanida's participation in sixth grade, an observer would not have recognized their patterns in seventh grade. They were "different students," partly because of the affordances and constraints of their classroom cultures.

We began with this account to illustrate the importance of understanding how motivation develops and why it changes. Teachers cite motivation as crucial for engagement and performance, and they want to know how to foster 
its development and change. Yet motivational research has not yet provided the kinds of information necessary to influence particular students' motivation in complex and specific classroom environments (Brophy, 2007). Researchers have tended to address questions about promoting students' motivation with generalized cognitive constructs such as goals, values, needs, or efficacy and identifying the statistical relations among them (Eccles, Wigfield, \& Schiefele, 1998). However, although research has identified important factors related to motivation (e.g., particular beliefs, perceptions of environments, demographic characteristics), it can provide only a general theoretical heuristic for understanding tendencies and does not explain individuals' behavior over time, as illustrated in our opening example of Justin and Shanida (e.g., Boekaerts, 1999). For educational research to be meaningful and useful to educators, it needs to interpret student behavior (e.g., indicators of motivation) as specific responses to specific sets of circumstances (Nuthall, 2004; Resnick, 1993). Pajares (2007) expressed this well when he noted,

Research findings ... drawn from educational psychology broadly, and motivation theory and research in particular ... are bounded by a host of situated, cultural factors that must be attended to if the constructs themselves are to have any, as William James (1907/1975) termed it, practical, or cash, value. (p. 30)

We believe that the way many of us have practiced motivation research (ourselves included) has lessened its "cash value" for practical concerns in education. Motivational constructs provide a starting point - knowing that students come to adopt different values, goals, or competence beliefs and how they are related to other beliefs and behaviors is certainly important. But we also need to know how students develop those competence and value beliefs, why they may fluctuate from time to time or place to place, and what outcomes evolve from such experiences. The study of beliefs alone cannot adequately answer these questions. As Bruner (1996) noted, "Although meanings are 'in the mind,' they have their origins and their significance in the culture in which they are created" (p. 3). Moreover, we believe it is only by attending to the dynamic, unfolding patterns of how individuals change in response to their context, and how contexts change in response to individuals' actions, that we can illuminate the development of motivation.

In this article we claim that much motivation research to date has separated individuals and their contexts and has failed to capture the dynamic and situational nature of motivation. These tendencies have limited researchers' ability to provide explanations of development and change in students' motivation to learn. We propose instead that motivation research take a situated view-one that treats the individual and the social and historical context holistically and dynamically. We are not the first to suggest this. Sivan (1986), Blumenfeld (1992), Paris and Turner (1994), Hickey (1997), and others have made similar calls, and the issue continues to garner attention at conferences and in special journal issues (Järvelä \& Volet, 2004) and edited books (e.g., Volet \& Järvelä, 2001). Nevertheless, there continues to be little motivation research that is framed consistently with the premises of holistic and situated guiding theoretical frameworks. As part of these efforts, researchers appear to be grappling with how to theoretically frame situated research. For example, some (e.g., Dermitzaki \& Efklides, 2001; Järvelä \& Niemivirta, 2001; Lemos, 2001; Middleton \& Perks, 2005; Volet, 2007) have combined premises and constructs inherent to sociocultural perspectives with motivational constructs that are derived from social cognitive motivational theories (e.g., goal orientations, perceived competence), whereas others (e.g., Hickey \& Granade, 2004) have maintained that social cognitive tenets are not compatible with sociocultural ones. In addition, researchers (e.g., Ainley, 2007; Ainley \& Hidi, 2002; Boekaerts, 2002; Järvelä, Salonen, \& Lepola, 2002; Järvenoja \& Järvelä, 2005; McCaslin \& Murdoch, 1991; Nolen, 2001, 2007; Nolen \& Ward, 2008; Op’t Eynde, DeCorte, \& Verschaffel, 2001; Salonen, Vauras, \& Kinnunen, 2007; Walker, Pressick-Kilborn, Arnold, \& Sainsbury, 2004) continue to develop procedures and methods for framing, collecting, and analyzing situated data. Overcoming these methodological challenges is vital before situated and holistic research can be conducted - research that will advance understanding of how and why motivation develops and changes - and is therefore the focus of this article.

Accordingly, we demonstrate how researchers might conduct situated motivation research. We present one approach from developmental psychology-Rogoff's (1997) three planes of analysis - that attempts to account for the situated nature of behavior. We then present examples of current motivation research to illustrate how this approach has been applied (albeit not explicitly by the researchers). We provide an explicit example of how one researcher conceptualized data collection and analysis from a situative perspective. Finally, we explain the value of this approach for motivation research. Our focus in this article is particularly related to motivation in classrooms.

\section{CONCERNS WITH CURRENT MOTIVATION RESEARCH}

\section{Separating Beliefs From Their Contexts}

As early as 1974, Maehr observed that "complex human behavior is seldom if ever solely a function of the person. ... Situations and contexts are critical in eliciting or maximizing any predisposition to achieve" (p. 64). Maehr was alluding to psychologists' tendency to treat persons and situations as dichotomies. This approach continues today, as much current motivation research (including ours, e.g., Patrick, Ryan, \& Pintrich, 1999; Turner et al., 1998) is focused 
predominantly on persons' "beliefs and cognitions, emphasizing psychological and interpretational process" (Eccles et al., 1998, p. 1022). Thus, individuals' general beliefs and interpretations of constructs and contexts (e.g., the meaning of competence, success, academic tasks, and purposes for students doing school work), and their interior cognitive processes are primary (Barone, Maddux, \& Snyder, 1997). Martin (2006) noted recently this same trend within educational psychology in general, in which

the image of the learner that remains constant is that of an individual representing the world and adjusting internal knowledge stores and schemata as different tasks seem to require. Interpersonal, social, and broader cultural contexts are seen as relevant, but are treated primarily as factors that must be considered as possibly affecting the specific learning strategies employed and the manner and consequences of their employment. (p. 595)

Yet ignoring students' beliefs is also problematic. In an attempt to consider context meaningfully, some recent research has focused on the classroom context almost exclusively. Again, this characterizes some of our research too (e.g., Patrick, Anderman, Ryan, Edelin, \& Midgley, 2001; Turner et al., 2002). Research focused primarily on the context has implicitly assumed that all students experience a classroom or teacher's instruction similarly. Common examples include aggregating students' reports within classrooms, which erases the differences among people and activities, and reporting what the teacher does while instructing the class as a whole, which assumes it is interpreted and experienced uniformly by all students.

Both approaches to research - focusing on the individual or on the context, either singly or consecutively-have resulted in a considerable accumulation of knowledge about students' motivation and the contexts in which people learn. Nevertheless, the research is less informative with respect to how and why motivation develops and changes.

\section{Stability of Persons and Consistency of Situations}

A second characteristic of much current motivation research relates to concerns with generalization - both about people and about situations. These generalizations lead to assumptions that both people and situations are more stable than they are, as expressed in Mischel's concern that psychologists confound stability with consistency. He argued that "people repeatedly observe someone behaving the same way in a particular situation [and] confuse stability of behavior (across occasions) with consistency (across situations)" (as cited in Barone et al., 1997, p. 136; see also Kindermann \& Valsiner, 1995; Mischel, 2004; Mischel \& Schoda, 1985; Ross \& Nisbett, 1991). That is, behavior is not stable (i.e., the same across different contexts) but is consistent (similar within the same context). For example, when researchers measure students' beliefs in English class, even on several different days, the tendency is to assume that this is representative of students' motivation in English in general. However, people are likely to behave quite differently in different contextseven ones that share many similar features, as illustrated by the analysis of Justin and Shanida. Indeed, change is the premise of motivation intervention research: When context changes, so does motivation (e.g., Ames, 1990; Maehr \& Midgley, 1996; Nicholls, 1989).

A classic example of how changes in context, despite many features remaining the same, elicit changes in people's behavior comes from a series of Kurt Lewin's studies in which he investigated differences in group dynamics. Lewin examined children's behavior within a mask-making club under one of three different leadership styles-democratic, authoritarian, and laissez-faire (Lewin, 1948; Lewin, Lippitt, $\&$ White, 1939). The children in the authoritarian-led group exhibited more hostile domination and criticism, and less cooperation and praise, than those in the democratic-led group. When children were transferred to other groups with different leadership styles, their behavior also changed markedly. A more recent research example, with findings consistent with Lewin's, examined the intrapersonal and interpersonal variability of flow using Hierarchical Linear Modeling (Schmidt, Shernoff, \& Csikszentmihalyi, 2007). Adolescents responded to flow questions (e.g., how happy or how much challenge they felt) when "beeped," and their responses were grouped by physical location (e.g., home, academic classes, nonacademic classes). Schmidt and her colleagues found greater variability in flow within persons rather than between them; about three fourths of the variation was at the individual level.

Contexts are also not typically stable. Changes within the same math class, for example, can constitute quite a different context. Such changes may include different topics within mathematics, different tasks, whether students work individually or in small groups, how students interact among each other, or whether the teacher is absent or having a "bad day." Nevertheless, in motivation research students are asked often to rate their beliefs across many situations or occasions, such as "in math class" or "at school." Doing so, though, implies that there is constancy as to how students experience math classes during a semester, or experience school with different subjects and teachers, or that such differences are minor and not important. This is an observation that applies to much research in psychology, as Kindermann and Valsiner (1995) observed, "Typically, context change across time is considered either irrelevant or is explicitly controlled; the focus is on interindividual differences that are examined as consequences of differences in earlier (or simultaneous) context conditions" (p. 228).

There is ample evidence, therefore, that we may construe or construct stability when, in fact, both people and situations are less predictable. Our concern about promoting motivation 
is premised on assumptions that motivations and motivated behaviors can and $d o$ change, both within and across contexts, and that contexts change as well. We argue that studying how change happens should be a major goal of motivation research.

\section{CONSIDERING INDIVIDUALS AND CONTEXTS IN TRANSACTION}

We have claimed that understanding development and change in motivation has been hampered by researchers' tendency to focus separately on individuals and on context and to overgeneralize from their data. Of interest, Dewey (1922) recognized this problem and offered the notion of transaction as a way to represent the "social" and "cognitive" together, as integral parts of a single phenomenon. He defined a transaction as the involvement of the "organism and environmental objects jointly at every instant of their occurrence, and in every portion of space they occupy [italics added]" (Dewey \& Bentley, 1949, pp. 122, 129). Thus, in line with Dewey, we argue that development and change in motivation can be understood only by examining the interplay (or transaction) between individuals and context, considered as a single phenomenon. As our illustration of Shanida and Justin demonstrated, it was only by considering students acting as part of the classroom experiences that we could explain or predict their participation in their math classes.

If researchers are to conceptualize behavior (including motivation) as the dynamic transaction of persons and their environments, they must attend to

processes of individuals' adaptation to changing contexts, ... processes of context adaptation to changing individuals, and [to] individuals' potential to instigate and shape the development of their contexts, as well as [to] contexts' potential to instigate and shape the developmental pathways of individuals. (Kindermann \& Valsiner, 1995, p. 230)

Because our present approaches to framing research seem limiting, we next present an alternative approach that better captures the situated nature of motivation.

\section{A SITUATED APPROACH TO MOTIVATION RESEARCH}

Our goal was to identify a research framework that will afford better understanding of both the how and why of motivationhow students' motivation is contextualized in particular activities, persons, discourse, and materials at specific places and times, and why it changes. We sought to represent student motivation in a way that acknowledges the social source of motivation, is situated and developmental, and treats the social and the cognitive holistically. In short, the approach we sought would need to capture people acting with others in particular cultural and historical settings over time.

We found Rogoff's $(1995,1997,2003)$ heuristic of three planes of analysis both appropriate and fruitful for motivation researchers. Rogoff $(1990,1995)$ builds on Vygotsky's (1978) two planes of analysis, which asserted that all learning appears first on the social plane, and then on the psychological plane. Like Vygotsky and activity theorists, and Dewey before them, Rogoff emphasizes the mutuality of individual and environment. She noted that

studying human events or activities contrasts with the more traditional approach of examining the individual in isolation or in interaction with a separate environment. In [Rogoff's and her colleagues'] approach, individuals' efforts and sociocultural practices are constituted by and constitute each other and thus cannot be defined independently of each other [italics added] or studied in isolation. (Rogoff, Baker-Sennett, Lacasa, \& Goldsmith, 1995, p. 45)

Substituting "motivation" for "individuals' efforts" in this quote is one way for us to begin to think about how to study motivation from this perspective. Central to Rogoff's (1990, 1995) approach is the unit of analysis. Activity or event is the unit of analysis because it preserves the holistic nature of phenomena rather than dividing events into separate elements, such as individuals and environments, or cognitive and social. She uses the term participation to bridge the individual and the environment-individuals participate with others in communities. Thus, her approach seeks to keep the functioning unit intact.

This participation plays out on three planes: personal, interpersonal, and community (Rogoff, 1995), with the cognitive and the social infused in each. The personal plane focuses on how individuals change through their participation in an activity (e.g., how does Jamal participate in his math group over the semester?). The interpersonal plane focuses on the ways in which activities (and materials) are communicated and coordinated among individuals and how they facilitate or hinder certain types of participation (e.g., how does the teacher communicate norms and how do group members participate [or not] with each other, including Jamal, over time?). The community plane focuses on institutional practices and cultural values which have developed over time (e.g., what is the instructional focus in this classroom, and how is it related to more societal or organizational influences such as immigration, high-stakes testing, or school reform?). Each plane acts on and is acted on by the others. For example, it would be difficult to understand the norms and interactions in Jamal's group (interpersonal level) without understanding the participants' roles in coconstructing them (personal level) and the classroom and school policies and values (community level).

Although the three planes are inseparable when activity is the level of analysis, each can serve as a focus of analysis 
(i.e., foreground) at different times with the others remaining in the background. "The parts making up a whole activity or event can be considered separately as foreground without losing track of their inherent interdependence in the whole. ... Foregrounding one plane of focus still involves the participation of the backgrounded planes" (Rogoff, 1995, p. 140).

That is, although it may be difficult to focus equally on all planes, it is not possible to gain understanding if any one plane is ignored - the approach requires all three planes be presented. Thus, when any one plane is placed in the foreground, the other planes need to be visible (albeit with less focus) in the background.

We believe that Rogoff's $(1997,2003)$ three planes of analysis is a useful organizing framework for motivation research. This approach takes account of the personal, interpersonal, and community planes and examines them in relation to each other. As we show with examples in the next section, researchers have foregrounded one (or sometimes more) planes while portraying the other planes in the background, "but always in relation to the whole" (Rogoff et al., 1995, p. 45).

\section{ROGOFF'S THREE PLANES}

\section{Personal Plane}

When the researcher foregrounds the personal plane, the focus is on how people change through their participation and come to engage later in similar activities (Rogoff, 1995). The "focus is on the active changes involved in an unfolding event or activity in which people participate" (p. 151). In the following example of research by Volet (1999a, 1999b), we illustrate the personal plane perspective especially, and how it illuminates and is illuminated by the other planes.

The transfer of students' learning-related processes across cultural-educational contexts. Volet (1999a, $1999 \mathrm{~b}$ ) summarized a body of research on both the success and difficulty of the acculturation of Confucian Heritage Culture (CHC) students from Hong Kong and Singapore into Australian university communities of practice. The research describes the perspectives of the two groups of students (personal plane) who had similar patterns of participation. In addition, Volet described their instructors' and Australian classmates' interactions with them (interpersonal plane) and the norms, including affordances and constraints, of the two different cultural-educational settings (community plane) to explain both the ease and difficulty of the students' changes. At each plane, Volet presented data addressing the nature of cognitive and social participation, together.

Using a corpus of survey, observational, and interview data, Volet analyzed CHC students' reports of attempts to participate in the new context by using learning-related dispositions and practices that had been successful in their home cultural-educational contexts (personal plane). For example, students reported that they formed informal study and support groups, revealing a high value for academic achievement, deep motives for learning, and emphasis on effort. At the same time, students reported seeking help from teachers outside of class, copying text verbatim in assignments, and low participation in tutorial settings. For example, in tutorial settings, $\mathrm{CHC}$ students attempted to transfer practices such as listening respectfully, not interrupting, and trying to find out an answer on their own before asking the instructor. Although these practices had been successful, even necessary, in the home setting, they were unsuccessful in the new setting.

Evidence from the interpersonal plane explains why such practices transferred poorly. Instructors expected all students to participate and ask questions during class and labeled CHC students as shy and dependent when they used "home practices." But CHC students were shocked by the seemingly rude Australian students' interruptions in tutorials to ask "the simplest questions" (Volet, 1999a, p. 635). Similarly, when $\mathrm{CHC}$ students tried to participate in ways consistent with instructors' expectations, their hesitancy with English in the midst of loud and vocal Australian students served as constraints on their attempts.

Community-level norms also helped explain the difficulty of applying "home" practices to a new community of practice. Culturally organized norms in each country offered affordances for each system's particular institutional practices. In Hong Kong and Singapore, high school systems were highly assessment oriented, with a common practice of testing for factual answers. In such a system, CHC students' modes of participation, such a looking for cues for how to complete tasks correctly and copying texts verbatim, were adaptive, even necessary, for passing examinations. Conversely, the Australian system valued independence, creativity, and student self-reliance. Thus, complementary information from the interpersonal (teachers and fellow students) and community planes (different institutional practices) help the reader understand both CHC students' difficulty and their eventual change in participation as they acculturated to a new community of practice.

Volet's analysis illustrates the context dependency of how individuals' beliefs (e.g., achievement goals) transact with contextual specifics and result in participation (e.g., selfregulatory behaviors). Although students reported learningoriented goals and study strategies, they were not successful in the new setting. This appears to contradict some of our assumptions about motivation. Strategies are not inherently "successful" and "unsuccessful" but are defined by the interpersonal norms of the situation and by their cultural fit with the organization of teaching and learning. To understand how and why students' behavior changed, we need to understand their motivational beliefs in transaction with the affordances and constraints of the situation, both present and historically. 


\section{Interpersonal Plane}

When the researcher foregrounds the interpersonal plane, the focus is on "how people communicate and coordinate efforts in face-to-face and side-by-side interaction" (Rogoff, 1997, p. 269), including the "routine, tacit communication and arrangements between children and their companions" (Rogoff, 1995, p. 148). This view also includes "direct interaction with others as well as engaging in or avoiding activities assigned, made possible, or constrained by others, whether or not they are in each other's presence or even know of each other's existence" (Rogoff, 1995, p. 147). We illustrate the interpersonal plane next by highlighting a portion of Gresalfi's (2004) study of the development of mathematical identities in classrooms, although, as Volet did in the previous example, she foregrounded all three planes at different points in the study.

\section{Middle school students' participation in mathemat-} ics. Gresalfi (2004) focused on two eighth-grade algebra classrooms over the course of a year to understand how students' participation was encouraged and established during that time-research that has implications for understanding mathematics motivation and competence. She presented analyses of eight specific students, four who were successful students and four who were not, in order to examine differences. Each student's participation was analyzed three times throughout the year, each time while participating in a different group of students. She used multiple sources and types of data, including transcriptions of videotaped lessons, detailed field notes, surveys, interviews with teachers and target students, and student work samples. She employed theoretical perspectives from dynamic systems theory, situative theory (Greeno \& Middle School Mathematics through Application Project Group [MMAP], 1998; Lave \& Wenger, 1991), and ecological psychology (Gibson, 1979), and linked her findings to ideas from attribution theory (Weiner, 1980). This analysis goes beyond describing behavior to analyzing how students come to participate in activities differently. Consistent with Rogoff's holistic view of participation, Gresalfi intertwined cognitive and social aspects throughout.

Gresalfi gave rich accounts of the two quite different classroom cultures, including how the teachers' values for participation and meanings of mathematics were communicated and how norms for students' interactions with tasks, each other, and the teacher evolved and played out (i.e., community plane). One classroom teacher strongly emphasized that it was important for her students to know why an answer was correct and that they were both expected and obligated to know how to approach and think through problems. She required that students work on math activities in small groups and that they help each other and discuss their ideas and procedures in their groups, which she changed every 2 weeks. She was committed to having students understand mathematical concepts, knew her students well as people, and created a respectful and supportive classroom environment. Students in general did engage with mathematical concepts, but not all students developed mathematical identities in this mathreform classroom environment. Gresalfi's account of specific students' participation over the year (i.e., personal plane) considered why students interacted with classroom practices so differently, and which specific practices actually offered opportunities for them to participate. She demonstrated how students' identities were constructed through patterns in the kinds of opportunities available to them and whether or not they took up such opportunities.

Dani, a girl in one class, had earned a B-in math the previous year but struggled in eighth-grade algebra, ultimately failing. Over the year she came to see herself as being a poor math student and in interviews near the end of the year expressed frustration with herself for not having put forth the effort necessary to be successful. However, she continued to participate in class and interacted frequently with group members, although she appeared to have little confidence in her ability and typically asked questions of group members before attempting problems. Thus, she did not come to understand the mathematical concepts and was ultimately not successful.

The interpersonal plane helps the reader understand how a previously successful student, in a seemingly supportive and learning-focused classroom, ultimately failed her mathematics class. From an analysis of how Dani interacted across the year with her different group members and with the mathematical content, Gresalfi showed how Dani's interpersonal interactions related to the type and quality of her participation. For example, on occasions when Dani worked with students who were themselves focused on learning algebra, who followed the teacher's norms of answering peer questions and explaining their thinking, and who were not easily distracted from the math tasks, Dani engaged most deeply with the content. Her own talk during group work tended to reflect this. This pattern was more typical of the beginning of the year. However, when her group members were her friends, she often became distracted from the math, moving off task. Similarly, on occasions when her group members resisted the teacher's instructions for collaboration and worked on tasks independently, the opportunities for developing mathematically were quite limited. At these times, Dani's interactions with group members tended to be social rather than content focused, or, at most, tended to involve procedural issues. Given that fewer of her groups were of the first type (she had many friends), Dani's opportunities for constructing understanding of algebra decreased over time, which made it more difficult for her to participate with content successfully. This pattern was typical of the end of the year.

Thus, in Gresalfi's three-framed analysis we see Dani as much more than a low-achieving student with low selfefficacy, who would like to do well in algebra but didn't believe she could, and who conformed to class norms of working on problems with her group. We also see more than 
a supportive and collaboratively focused classroom, led by an enthusiastic and knowledgeable teacher, with students who typically talked in small groups about a variety of ways to solve challenging algebraic puzzles. We see changes in the direction and quality of Dani's participation associated differentially with her responses to different opportunities and group compositions. Therefore, we can richly appreciate reasons for her increasingly impoverished participation in algebra, and her decreasing success, and understand the process by which these changes came about.

\section{Community Plane}

When a researcher foregrounds the community plane, the intent is to focus on "people participating with others in culturally organized activity, with institutional practices and development extending from historical events into the present, guided by cultural values and goals" (Rogoff, 1997, p. 269).

\section{Students' motivation and achievement as situated} in their school and classroom cultures. Boaler (2002) conducted a 3-year study in two comprehensive schools in her native England to document the situated nature of mathematics teaching and learning. Guiding her research was the contention that "knowledge, rather than being a free standing, transferable entity, is shaped or constituted by the situation or context in which it is developed or used" (p. 2). Boaler foregrounded the community plane to help "discover whether different teaching approaches would influence the nature of the knowledge that students developed and the ways that students approached new and different situations" (p. 2).

The community plane was viewed through three complementary lenses. First, Boaler situated this study within the context of historical discussions of both learning theory and educational reform. Specifically, she addressed the concern that students are not able to use, or transfer, the mathematics that they learn in school to situations outside the classroom. She related this to traditions of teaching mathematics in England, which includes explaining methods from the chalkboard for the first portion of the lesson and then giving students practice problems from their textbooks. From a motivational perspective, such instruction fails to address meaningfulness and relevance, thus contributing to lack of interest in and value for mathematics.

Second, Boaler provided portraits of the two schools, their demographics, history, traditions, philosophies of learning, and practices. The schools had strikingly similar demographics. Both schools were open to any applicant, enrolled primarily White and working-class students, and were considered low achieving in their districts. Despite the similarity of student populations, the schools had quite different traditions and philosophies.

Amber Hill School appeared respectable and traditional, from the physical spaces to the fact that students were required to wear uniforms. The principal governed the school with little input from others and walked the halls enforcing order. Classrooms were traditional and orderly, with students seated and looking at the board. After the first semester of their 4 years at Amber Hill, students were divided into eight different ability grouped classes, where they remained.

Phoenix Park School was progressive and described as peaceful, and students were soft spoken and orderly in the halls. Teachers explained that rules did not govern student behavior as much as the general atmosphere in the school. Students wore casual clothes, not uniforms. Phoenix Park had a thriving special needs program and stressed equality of opportunity for all students. Students were expected to take responsibility for their learning and were allowed to work unsupervised often. Students worked in mixed ability mathematics classes for all but the last several months of their time at Phoenix Park.

Third, as Boaler vividly described, the traditions, norms, and values in each school extended to the teachers and to their mathematics classrooms. At Amber Hill, mathematics teachers strongly supported the traditional curriculum they had adopted. The teachers shared a belief that if they explained mathematical methods clearly, the students would understand and learn. They emphasized rules and procedures during quick-paced lessons. They also assigned a large amount of practice exercises. Students worked in textbooks almost exclusively, with 3 weeks each year devoted to investigations or open-ended tasks. The teachers were confident that if they covered the national curriculum, students would do well on the national examination. However, students reported boredom, anxiety, and difficulty transferring the procedurally oriented instruction to conceptual problem solving, possibly because of lack of relevance.

At Phoenix Park, school philosophy was also reflected in the mathematics curriculum. Students worked on open-ended projects in every lesson until time to review for the national examination in their last year. Textbooks were rarely used, and students in all classes worked in mixed ability groups. Teachers introduced a project through discussions with students and students worked on the problems using their own ideas. Teachers introduced new methods as groups or individuals needed them. In contrast to the whole-group lessons and compliant "time on task" behavior in the Amber Hill classrooms, students at Phoenix Park were given many choices and were expected to regulate their own learning. This more laissez-faire approach, intended to foster autonomy, cooperation, and meaningfulness, nevertheless resulted in about $30 \%$ of the students appearing "off task" when tallied.

These classroom cultures were described both on the interpersonal and personal planes with excerpts of classroom instruction, including teacher-student discourse and with extensive interviews with students about many topics, ranging from views of mathematics to enjoyment and agency. For example, on the interpersonal plane, Boaler examined the discourse during math lessons at Phoenix Park. She demonstrated how the teacher and students had established norms 
that supported challenge and meaningful work. It seems clear that the teacher pressed students for explanations and set high standards. She asked students, "If someone new came into class and asked you what makes a good piece of work, what does Ms. Thomas like; what would you say?" Students responded with "lots of writing," "have an aim," and "write about patterns." The teacher challenged them with "what does a good plan look like?" and "there must be some sense to it" (Boaler, 2002, pp. 61-62). Boaler reported that many students struggled but that they sat around the blackboard engaged in this discussion for some time, indicating that the mathematics was interesting and worthwhile. Interpersonal exchanges like this helped demonstrate how the norms were established, maintained, and challenged.

On the personal plane, Boaler reported both the differences among students' views of their math classes at Phoenix Park and how some of those views changed over time. For example, she noted that during their 1st year, a small subgroup (mostly boys) in each mathematics class disliked the open nature of the instruction. When asked what he thought when he went into a math lesson, Shaun replied, "When I go into a maths lesson, I usually sit down and I think, who am I going to throw [an eraser] at today?" A classmate replied, "Messing about, that's what I enjoy doing." These boys appeared to resist the opportunity they were given for autonomy and the challenges it entailed; they expressed preference for being told what to do. Because of teacher attention to specific students' needs over the course of several years (such as the discussion of "a good piece of work"), however, these same disaffected boys eventually came to value the high expectations and relevance of their mathematics lessons.

It is difficult to explain the changes in the boys' behavior and attitudes without understanding features of the interpersonal plane, such as how the teacher and students established norms related to challenge and meaningfulness. Similarly, knowing that Amber Hill and Phoenix Park school cultures and philosophies differed helped explain how instruction was conceptualized, and why many students reported different attitudes, interest, and effort at the two schools. Boaler helped readers see how the social and cultural norms were reflected in what students learned and in their motivation to learn, entwining both the social and cognitive. Thus, understanding the interpersonal and community culture helps explain change in motivation over time.

\section{CONDUCTING SITUATED RESEARCH: DATA COLLECTION AND DATA ANALYSIS}

The approach which we advocate is challenging. How do researchers capture and analyze data that are situated, dynamic, multidimensional, and emerging in social learning activities? How does one integrate data across the three planes and how does one represent such transactions to readers? Choices such as these must rely first on one's specific research questions and underlying theory. However, to illustrate one researcher's approach, we take a closer look at Gresalfi's (2004) data collection and analysis with a view to providing one example.

Gresalfi's (2004) research question focused on how students' mathematical identities developed over the school year. She theorized identity development as a transaction between the kinds of opportunities that are offered and students' sensitivities $^{2}$ to, or inclinations to take up, these opportunities. Students' different sensitivities led to different patterns of participating with others. Her focus was on who participated, when they participated, and how they participated in their different classroom systems.

\section{Data Collection}

Gresalfi designed data collection in response to her specific research questions. Data were also amenable to interpretation at personal, interpersonal, and community planes (Rogoff, 1997). These have been summarized in Table 1 to provide an overview of types and frequencies of data.

\section{Data Analysis}

Data collection, though targeted to research questions, does not really reveal how Gresalfi derived her rich findings. Decisions about data analysis provide more insight into how she captured situated, dynamic, and emerging patterns and how she integrated data from the three planes. Based on her premise that identities were constructed in opportunities to make connections among ideas and to work with others, and students' sensitivities to such opportunities, these two constructs became major categories of analysis. These categories use activity as the unit of analysis, capture transactions among people and materials, and incorporate all three planes.

Opportunities were categorized in three possible domains: (a) working with content, (b) working with others (on content or on organization), and (c) being off task. Working with content and working with others were further classified qualitatively as (a) forceful (i.e., requiring participation) or (b) moderate or weak (i.e., providing an occasion for participation). Opportunities might come from the task, from group mates, or from the teacher.

Sensitivities helped explain the trajectory of change or stability in patterns. Did the student take up, renegotiate, or ignore an opportunity? When forceful opportunities were taken up, they were more likely to change stable patterns of understanding or participation. When students took up weak

\footnotetext{
${ }^{2}$ Gresalfi (2004) acknowledged that "sensitivities," although descriptive, remain a "black box" awaiting further research. She did not investigate the source of sensitivities but hypothesized that they may arise from several sources. Sensitivities to mathematical opportunities might come from perceiving oneself as a "math person," from professing mastery goals, and from perceptions of competence and control. Sensitivities to working with others might derive from a sense that "being good at math" meant offering good explanations to others.
} 
TABLE 1

Data Collection Matched to Research Questions

\begin{tabular}{|c|c|c|}
\hline Research Questions & Data Collected & Frequency \\
\hline $\begin{array}{l}\text { Community plane } \\
\text { How were classroom norms and content } \\
\text { emphases established? }\end{array}$ & $\begin{array}{l}\text { Observations, transcribed videotapes, and field } \\
\text { notes to document how students interacted with } \\
\text { the domain of mathematics } \\
\text { Interviews with teachers } \\
\text { Student work samples }\end{array}$ & $\begin{array}{l}1 \times \text { week August-September } \\
2 \times \text { week October-January } \\
\text { Daily during a math unit in February } \\
2 \times \text { week March-May }\end{array}$ \\
\hline Interpersonal plane & & \\
\hline How did students' participation change over time? & $\begin{array}{l}\text { Transcribed videotapes } \\
\text { Interviews }\end{array}$ & $\begin{array}{l}\text { (see previous) } \\
3 \text { during the year }\end{array}$ \\
\hline Why did it change/not change? & & \\
\hline Personal plane & & \\
\hline $\begin{array}{l}\text { What do students think about themselves as } \\
\text { mathematics learners? } \\
\text { What are their ideas and beliefs about } \\
\text { mathematics? }\end{array}$ & Interviews & 3 during the year \\
\hline Personal plane & & \\
\hline $\begin{array}{l}\text { What were students' perspectives of the observed } \\
\text { events and patterns in the classroom? }\end{array}$ & $\begin{array}{l}\text { Surveys } \\
\text { Interviews }\end{array}$ & $\begin{array}{l}3 \text { surveys } \\
3 \text { during the year }\end{array}$ \\
\hline
\end{tabular}

opportunities or generated opportunities themselves, Gresalfi interpreted this as evidence of sensitivity to those types of opportunities. Students with weaker sensitivities to the content, like Dani, were more successful when opportunities were forceful and less successful when they were weak.

Students' sensitivities to opportunities were both situated and dynamic. Gresalfi (2007) viewed identity development as a self-organizing system that settled into patterns over time. The trajectory was influenced both by initial motivational states such as students' competence, values, and goals, as well as opportunities to make connections between ideas. To capture how participation patterns originated and evolved over the year, she focused analysis at three levels: participation from moment to moment, during a specific day, and across the year. First, students' trajectories were considered at a global level: Were students on or off task and were they working independently or with others? Then, students' conversations were analyzed for explanations that they offered to each other and how or if they held each other accountable.

For moment-to-moment interaction, Gresalfi focused on the opportunities presented to the students and whether, when, and how individual students took up the opportunity. In transcripts of group interaction, students were arrayed in individual columns such that when one student was speaking, one could see what other students were doing simultaneously (e.g., yawning, looking puzzled, interrupting, working independently). Thus, student behavior was related to the strength of opportunities to work with others, to work with others on content, to the affordances of the mathematical task, and to the teacher's role. Then Gresalfi considered how a student participated over the course of the day. If there were noticeable points when the student's participation changed, what seemed to be catalysts for the change? After the path of a student's trajectory was determined for a daily episode, Gresalfi constructed a pictorial representation to illustrate the student's trajectory in a three-dimensional state space, allowing comparison of within and across student trajectories. Finally, Gresalfi considered how a student's participation developed over the course of the year - was the student's participation relatively constant over the year? Did it change? If it changed, when and in response to what kinds of opportunities did changes occur? For example, the opportunities offered and taken up in Dani's change of group membership proved important in her development. Over this time she may have come to be regarded as a "certain kind of person" by the classroom participant community, further shaping her interactions with others and with the content.

Gresalfi's analyses captured students' sensitivities to act in response to qualitatively different opportunities as they changed over time. Opportunities were situated in classrooms with different norms and teacher activity, different tasks, and with different group members. The thread which united the situational and dynamic events was how individual students responded to the affordances and constraints of opportunities. By analyzing patterns of activity among more and less successful students, Gresalfi derived some generalizations about how opportunities and sensitivities form developmental trajectories for different students. That is, her research demonstrates how and why students' motivation develops over time.

Although illuminating, Gresalfi's methodology remains specific to her research questions. We assume, however, that a multimethod approach is common to researchers investigating the kinds of questions we propose. Researchers will collect many kinds of data, quantitative and qualitative, and data will be longitudinal. As Gresalfi's work demonstrated, 
data may be amenable to analysis on all three planes. Thus, although researchers may collect the same kinds of data (e.g., video analysis, observations, interviews), the methods and theories used to analyze data will differ by research question.

\section{THE CONTRIBUTION OF THE THREE PLANES FRAMEWORK TO MOTIVATION RESEARCH}

Researchers have identified many student beliefs related to, and predictive of, their motivation (Eccles et al., 1998). However, the field of motivation has learned considerably less about how individuals come to hold these beliefs, or why or in what circumstances certain patterns of beliefs and behaviors play out, rather than in others. We believe that motivation researchers should focus more on development and change in motivation - issues that are central to fostering motivation to learn in the classroom, and that can be related to specific classroom interactions and activities. Such analyses provide a more ecologically valid understanding of students' motivation.

Conceptualizing motivation as a transaction between the cognitive and social enables researchers to examine and explain how motivated behavior develops and changes. We found Rogoff's perspective valuable for our objective, because it views contexts as people and their situated action, embedded in time and changing from moment to moment. The three planes help us remove the "boundaries" between person and environment, but they also help us focus on the constituent elements of the process as they work together. This view, although not denying the existence and importance of persons and their beliefs, also asserts that persons and their behavior cannot be understood outside of their social, cultural and historical contexts. We believe that approaches similar to these can help us meet some of the challenges still facing motivational research, including documenting the social source of motivation and understanding the holistic nature of motivation over time.

This three planes approach can inform practice because it chronicles participation in daily activity, making the explanations accessible to educators. Much motivation research analyzes relationships among variables. Variables neither map easily onto teachers' terrain, which is that of students participating in activities, nor provide the particulars necessary to understand and foster motivation in classrooms. Seen from the viewpoint of variables, Dani's (in Gresalfi, 2004) low self-efficacy for algebra, coupled with her low achievement, is consistent with typical findings in motivation research. However, this information does not help us understand how her self-efficacy came to decrease after having done reasonably well at math the previous year, and why Dani did not learn algebra despite being in an apparently positive learning environment. These are the types of questions that motivation researchers must be able to answer, though, if their research is to make a difference in classrooms. Gresalfi's portrayal showed how Dani's participation changed as she worked in different small groups, thus changing the opportunities and constraints she experienced. In this case, analyzing students' participation in groups, and how groups construe tasks differently, offers teachers a useful heuristic to view the complex nature of learning and motivation.

This article was inspired by our search for a conceptualization of motivation that would contribute to research about change and development of motivation. These ideas are not original to us - indeed, we have learned and borrowed from psychologists who have studied the situated nature of learning and development for a while (e.g., Bronfenbrenner, 1989; Bruner, 1996; Friedman \& Wachs, 1999; Greeno \& MMAP, 1998; Kindermann \& Valsiner, 1995; Magnusson, 1992; McCaslin, 2004; Plaut \& Markus, 2005; Wertsch, 1998). Nevertheless, they have not yet had the impact on educational psychology and motivation research that we believe could be valuable. We hope that this article will prompt more motivational research that bridges theory and practice, and that addresses the person and the context in transaction. This will take us further along the road to understanding how motivation develops and why it changes.

\section{ACKNOWLEDGMENTS}

An earlier version of this article was presented at the biennial meeting of the European Association for Research on Learning and Instruction, Nicosia, Cyprus, September 2005. We thank Phyllis Blumenfeld, Stuart Karabenick, Mary McCaslin, Debra Meyer, Susan Nolen, Frank Pajares, Tim Urdan, Richard Walker, Gale Sinatra, and the two reviewers for their invaluable feedback on previous versions.

\section{REFERENCES}

Ainley, M. (2007, August). Investigating the interconnections between dynamic learning processes: What does on-line measurement offer? In S. Karabenick (Chair), On the dynamic interplay of motivation theory and research methodology. Symposium conducted at the biennial meeting of the European Association for Research on Learning and Instruction, Budapest, Hungary.

Ainley, M., \& Hidi, S. (2002). Dynamic measures for studying interest and learning. In P. R. Pintrich \& M. L. Maehr (Eds.), Advances in motivation and achievement. Volume 12: New directions in measures and methods (pp. 43-76). Amsterdam: Elsevier.

Ames, C. (1990, April). Achievement goals and classroom structure: Developing a learning orientation in students. Paper presented at the annual meeting of the American Educational Research Association, Boston.

Barone, D. F., Maddux, J. E., \& Snyder, C. R. (1997). Social cognitive psychology: History and current domains. New York: Plenum.

Blumenfeld, P. (1992). Classroom learning and motivation: Clarifying and expanding goal theory. Journal of Educational Psychology, 84, 272-281.

Boaler, J. (2002). Experiencing school mathematics: Traditional and reform approaches to teaching and their impact on student learning. Mahwah, NJ: Erlbaum. 
Boekaerts, M. (1999). Motivated learning: Studying student $\times$ situation transactional units. European Journal of Psychology of Education, 14, 41-55.

Boekaerts, M. (2002). The on-line motivation questionnaire: A self-report instrument to assess students' context sensitivity. In P. R. Pintrich \& M. L. Maehr (Eds.), Advances in motivation and achievement. Volume 12: New directions in measures and methods (pp. 77-120). Amsterdam: Elsevier.

Bronfenbrenner, U. (1989). Ecological systems theory. In R. Vasta (Ed.), Annals of child development (pp. 187-249). Greenwich, CT: JAI Press.

Brophy, J. (2007, April). Future directions in motivation theory and research. Paper presented at the annual meeting of the American Educational Research Association, Chicago.

Bruner, J. (1996). The culture of education. Cambridge, MA: Harvard University Press.

Dermitzaki, I., \& Efklides, A. (2001). Age and gender effects on students' evaluations regarding the self and task-related experiences in mathematics. In S. Volet \& S. Järvelä (Eds). Motivation in learning contexts: Theoretical advances and methodological implications (pp. 271-293). Amsterdam: Elsevier

Dewey, J. (1922). Human nature and conduct: An introduction to social psychology. New York: Henry Holt. [Republished as Boydston, J. A. (Ed.). John Dewey: The middle works, 1899-1924. Volume 14: 1922. Carbondale, IL: Southern Illinois University Press.]

Dewey, J., \& Bentley, A. F. (1949). Knowing and the known. Boston: Beacon.

Eccles, J. S., Wigfield, A., \& Schiefele, U. (1998). Motivation to succeed. In W. Damon (Series Ed.) \& N. Eisenberg (Vol. Ed.), Handbook of child psychology: Vol. 3. Social, emotional, and personality development (5th ed., pp. 1017-1095). New York: Wiley.

Friedman, S. L., \& Wachs, T. D. (1999). Measuring environment across the life span. Washington, DC: American Psychological Association.

Gibson, J. J. (1979). The ecological approach to visual perception. Boston: Houghton Mifflin.

Greeno, J. G., \& the Middle School Mathematics through Application Project Group. (1998). The situativity of knowing, learning, and research.American Psychologist, 53, 5-26.

Gresalfi, M. S. (2004). Taking up opportunities to learn: Examining the construction of participatory mathematical identities in middle school classrooms. Unpublished doctoral dissertation, Stanford University, Stanford, CA.

Gresalfi, M. S. (2007). Positioning in practice: Constructing trajectories of participation in algebra classrooms. Manuscript submitted for publication.

Hickey, D. T. (1997). Motivation and contemporary socio-constructivist instructional perspectives. Educational Psychologist, 32, 175-193.

Hickey, D. T., \& Granade, J. B. (2004). The influence of sociocultural theory on our theories of engagement and motivation. In D. M. McInerney \& S. Van Etten (Eds.), Big theories revisited (pp. 223-247). Greenwich, CT: Information Age.

Järvelä, S., \& Niemivirta, M. (2001). Motivation in context: Challenges and possibilities in studying the role of motivation in new pedagogical cultures. In S. Volet \& S. Järvelä (Eds.), Motivation in learning contexts: Theoretical advances and methodological implications (pp. 105-127). Amsterdam: Elsevier.

Järvelä, S., Salonen, P., \& Lepola, J. (2002). Dynamic assessment as a key to understanding student motivation in a classroom context. In P. R. Pintrich \& M. L. Maehr (Eds.), Advances in motivation and achievement. Volume 12: New directions in measures and methods (pp. 207-240). Amsterdam: Elsevier.

Järvelä, S., \& Volet, S. (2004). Motivation in real-life, dynamic, and interactive learning environments: Stretching constructs and methodologies. European Psychologist, 9, 193-197.

Järvenoja, H., \& Järvelä, S. (2005). How students describe the sources of their emotional and motivational experiences during the learning process: A qualitative approach. Learning and Instruction, 15, 465-480.
Kindermann, T. A., \& Valsiner, J. (1995). Directions for the study of developing person-context relations. In T. A. Kindermann \& J. Valsiner (Eds.), Development of person-context relations (pp. 227-240). Mahwah, NJ: Erlbaum.

Lave, J., \& Wenger, E. (1991). Situated learning: Legitimate peripheral participation. New York: Cambridge University Press.

Lemos, M. S. (2001). Context-bound research in the study of motivation in the classroom. In S. Volet \& S. Järvelä (Eds.), Motivation in learning contexts: Theoretical advances and methodological implications (pp. 129-147). Amsterdam: Elsevier.

Lewin, K. (1948). Experiments in social space. In K. Lewin \& G. W. Lewin (Eds.), Resolving social conflicts: Selected papers on group dynamics (pp. 71-83). New York: Harper \& Row.

Lewin, K., Lippitt, R., \& White, R. K. (1939). Patterns of aggressive behavior in experimentally created "social climates." Journal of Social Psychology, 10, 271-299.

Maehr, M. L. (1974). Sociocultural origins of achievement. Monterey, CA: Brooks/Cole.

Maehr, M. L., \& Midgley, C. (1996). Transforming school cultures. Boulder, CO: Westview.

Magnusson, D. (1992). Back to the phenomena: Theory, methods and statistics in psychological research. European Journal of Personality, 6, 1-14.

Martin, J. (2006). Social cultural perspectives in educational psychology. In P. Alexander \& P. Winne (Eds.), Handbook of educational psychology (2nd ed., pp. 595-614). Mahwah, NJ: Erlbaum.

McCaslin, M. (2004). Coregulation of opportunity, activity, and identity in student motivation: Elaborations on Vygotskian themes. In D. M. McInerney \& S. Van Etten (Eds.), Big theories revisited (pp. 249-274). Greenwich, CT: Information Age.

McCaslin, M. M., \& Murdock, T. B. (1991). The emergent interaction of home and school in the development of students' adaptive learning. In M. L. Maehr \& P. R. Pintrich (Eds.), Advances in motivation and achievement: Volume 7 (pp. 213-259). Greenwich, CT: JAI Press.

Middleton, M., \& Perks, K. (2007). Motivation for mastery: Mastery motivation as a socially constructed form of engagement. Manuscript submitted for publication.

Mischel, W. (2004). Toward an integrative science of the person. Annual Review of Psychology, 55, 1-22.

Mischel, W., \& Schoda, Y. (1985). A cognitive-affective system theory of personality: Reconceptualizing situations, dispositions, dynamics, and invariance in personality structure. Psychological Review, 49, 229258.

Nicholls, J. G. (1989). The competitive ethos and democratic education. Cambridge, MA: Harvard University Press

Nolen, S. B. (2001). Constructing literacy in the kindergarten: Task structure, collaboration, and motivation. Cognition and Instruction, 19, 95142 .

Nolen, S. B. (2007). Young children's motivation to read and write: Development in social contexts. Cognition and Instruction, 25, 219-270.

Nolen, S. B., \& Ward, C. J. (2008). Sociocultural and situative research on motivation. In M. Maehr, S. Karabenick, \& T. Urdan (Eds.), Social psychological perspective on motivation and achievement: Advances in motivation and achievement (Vol. 15, pp. 428-460). London: Emerald Group.

Nuthall, G. (2004). Relating classroom teaching to student learning: A critical analysis of why research has failed to bridge the theory-practice gap. Harvard Educational Review, 74, 273-306.

Op't Eynde, P., De Corte, E., \& Verschaffel, L. (2001). "What to learn from what we feel?": The role of students' emotions in the mathematics classroom. In S. Volet \& S. Järvelä (Eds.), Motivation in learning contexts: Theoretical advances and methodological implications (pp. 149-167). Amsterdam: Elsevier

Pajares, F. (2007). Culturalizing educational psychology. In F. Salili \& R. Hoosain (Eds.), Culture, motivation and learning: A multicultural perspective (pp. 19-42). Greenwich, CT: Information Age. 
Paris, S. G., \& Turner, J. C. (1994). Situated motivation. In P. R. Pintrich, D. R. Brown, \& C. E. Weinstein (Eds.), Student motivation, cognition, and learning: Essays in honor of Wilbert J. McKeachie (pp. 213-237). Hillsdale, NJ: Erlbaum.

Patrick, H., Anderman, L. H., Ryan, A. M., Edelin, K., \& Midgley, C. (2001). Teachers' communication of goal orientations in four fifth-grade classrooms. The Elementary School Journal, 102, 35-58.

Patrick, H., Ryan, A. M., \& Pintrich, P. R. (1999). The differential impact of extrinsic and mastery goal orientations on males' and females' self-regulated learning. Learning and Individual Differences, 11, 153171.

Plaut, V., \& Markus, H. (2005). The "inside" story: A cultural-historical analysis of being smart and motivated, American style. In C. S. Dweck \& A. J. Elliot (Eds.), Handbook of competence and motivation (pp. 457488). New York: Guilford.

Resnick, L. B. (1993). Shared cognition: Thinking as social practice. In L. B. Resnick, J. M. Levine, \& S. D. Teasley (Eds.), Perspectives on socially shared cognition (pp. 1-22). Washington, DC: American Psychological Association

Rogoff, B. (1990). Apprenticeship in thinking: Cognitive development in social context. New York: Oxford University Press.

Rogoff, B. (1995). Observing socio-cultural activity on three planes: Participatory appropriation, guided participation, and apprenticeship. In J. V. Wertsch, P. D. Rio, \& A. Alvarez (Eds.), Socio-cultural studies of mind (pp. 139-164). Cambridge, UK: Cambridge University Press.

Rogoff, B. (1997). Evaluating development in the process of participation: Theory, methods, and practice building on each other. In E. Amsel \& K A. Renninger (Eds.), Change and development: Issues of theory, method. and application (pp. 265-285). Mahwah, NJ: Erlbaum.

Rogoff, B. (2003). The cultural nature of human development. New York Oxford University Press.

Rogoff, B., Baker-Sennett, J., Lacasa, P., \& Goldsmith, D. (1995). Development through participation in socio-cultural activity. In J. Goodnow, P. Miller, \& F. Kessel (Eds.), Cultural practices as contexts for development (pp. 45-65). San Francisco: Jossey-Bass.

Ross, L. \& Nisbett, R. E. (1991). The person and the situation: Perspectives of social psychology. New York: McGraw-Hill.

Salonen, P., Vauras, M., \& Kinnunen, R. (2007, August). Motivation and emotion in context challenging research methodologies. In S. Karabenick (Chair), On the dynamic interplay of motivation theory and research methodology. Symposium conducted at the biennial meeting of the
European Association for Research on Learning and Instruction, Budapest, Hungary.

Schmidt, J. A., Shernoff, D. J., \& Csikszentmihalyi, M. (2007). Individual and situational factors related to the experience of flow in adolescence: A multilevel approach. In A. D. Ong \& M. van Dulmen (Eds.), Oxford handbook of methods in positive psychology (pp. 542-558). New York: Oxford University Press.

Sivan, E. (1986). Motivation in social constructivist theory. Educational Psychologist, 21, 209-233.

Turner, J. C., Meyer, D. K., Cox, K. E., Logan, C., DiCintio, M., \& Thomas, C. (1998). Creating contexts for involvement in mathematics. Journal of Educational Psychology, 90, 730-745.

Turner, J. C., Midgley, C., Meyer, D. K., Gheen, M., Anderman, E. A., Kang, J., et al. (2002). The classroom environment and students' reports of avoidance strategies in mathematics: A multi-method study. Journal of Educational Psychology, 94, 88-106.

Turner, J. C., \& Patrick, H. (2004). Motivational influences on student participation in classroom learning activities. Teachers College Record, 106, 1759-1785.

Volet, S. (1999a). Learning across cultures: Appropriateness of knowledge transfer. International Journal of Educational Research, 31, 625643.

Volet, S. (1999b). Motivation within and across cultural-educational contexts: A multi-dimensional perspective. In T. Urdan (Ed.), The role of context: Advances in motivation and achievement (Vol. 11, pp. 185-231). Stamford, CT: JAI Press.

Volet, S. (2007, August). Studying motivational dynamics within and across socially challenging learning activities: Grappling with methodological implications. In S. Karabenick (Chair), On the dynamic interplay of motivation theory and research methodology. Symposium conducted at the biennial meeting of the European Association for Research on Learning and Instruction, Budapest, Hungary.

Volet, S., \& Järvelä, S. (2001). Motivation in learning contexts: Theoretical advances and methodological implications. Amsterdam: Elsevier

Vygotsky, L. S. (1978). Mind and society: The development of higher mental processes. Cambridge, MA: Harvard University Press.

Walker, R. A., Pressick-Kilborn, K., Arnold, L. S., \& Sainsbury, E. J. (2004). Investigating motivation in context: Developing sociocultural perspectives. European Psychologist, 9, 245-256.

Weiner, B. (1980). Human motivation. New York: Holt, Rinehart \& Winston. Wertsch, J. (1998). Mind as action. New York: Oxford University Press. 
Copyright of Educational Psychologist is the property of Lawrence Erlbaum Associates and its content may not be copied or emailed to multiple sites or posted to a listserv without the copyright holder's express written permission. However, users may print, download, or email articles for individual use. 